\title{
A Recurrent Huge Sequestered Lumbar Disc Treated with Non-Operative Measures
}

\author{
Pyeong-Soo Kim, Junseok W. Hur, Jang-Bo Lee, Jung Yul Park ${ }^{凶}$ \\ Department of Neurosurgery, Korea University College of Medicine, Korea University Anam Hospital, Seoul, Korea
}

Lumbar disc herniation (LDH) is a common cause of lower back pain and sciatica. It is usually benign in majority cases. However, massive extrusion and sequestration are generally treated with surgical evacuation due to accompanying neurologic deficits and intolerable pain. In this report, we present a case of 75-year-old man with severe leg pain and paresthesia caused by recurrent extremely large herniated disc which was significantly improved with conservative treatment including nerve blocks and pulsed radiofrequency treatment.

Key Words: Lumbar; Disc; Sequestration; Recurrent; Conervative management.

$\triangle$ Corresponding author: Jung Yul Park, Department of Neurosurgery, Korea University College of Medicine, Korea University Anam Hospital, 73 Inchon-ro, Seongbuk-gu, Seoul 02841, Korea. Tel: 82-2-920-5729, Fax: 82-2-929-0629, E-mail: jypark98@korea.ac.kr

\section{INTRODUCTION}

Lumbar disc herniation (LDH) is a common cause of lower back pain and sciatica ${ }^{3,23)}$. In spite of many decades of study results, the natural history of LDH is not fully uncovered and there is no solid indications for surgical intervention. The majority of patients suffering from radiculopathy caused by $\mathrm{LDH}$ recover spontaneously without surgical intervention ${ }^{3,12,24)}$. In case of ruptured (without continuity) disc, several studies have demonstrated that these discs have great tendency to decrease in size with conservative management ${ }^{1,5,7,8,15-17,20)}$. However, large disc herniation generally cause neurologic deficit and unbearable pain which easily eventually lead to surgical intervention $^{18)}$. We present a case of extreme-large recurrent disc herniation treated without surgical intervention with good result.

\section{CASE REPORT}

A 75-year-old male was referred to the our neurosurgical department with a 3 months history of recurrent lower back pain and radiating bilateral leg pain after repeated operations. The patient suffered from intermittent lower back pain for several years. Four months ago, the symptom was aggravated and right lateral leg pain was newly developed. From another institute, lumbar 3/4 disc herniation was diagnosed and posterior approach right hemipartial laminectomy and discectomy were performed (Fig. 1A). Post-operative day 7, pain recurred and the follow-up magnetic resonance imaging (MRI) revealed recurrent disc herniation on same operated level (Fig. 1B). Revision surgery was performed at the same clinic. Symptom improved postoperatively but aggravated again after 3 weeks. He received rehabilitation therapy for 3 months without any improvement. He was referred to our institute then and MRI scan was taken that showed huge recurrent large disc herniation on the right side at L3/4 level severely compressing root and thecal
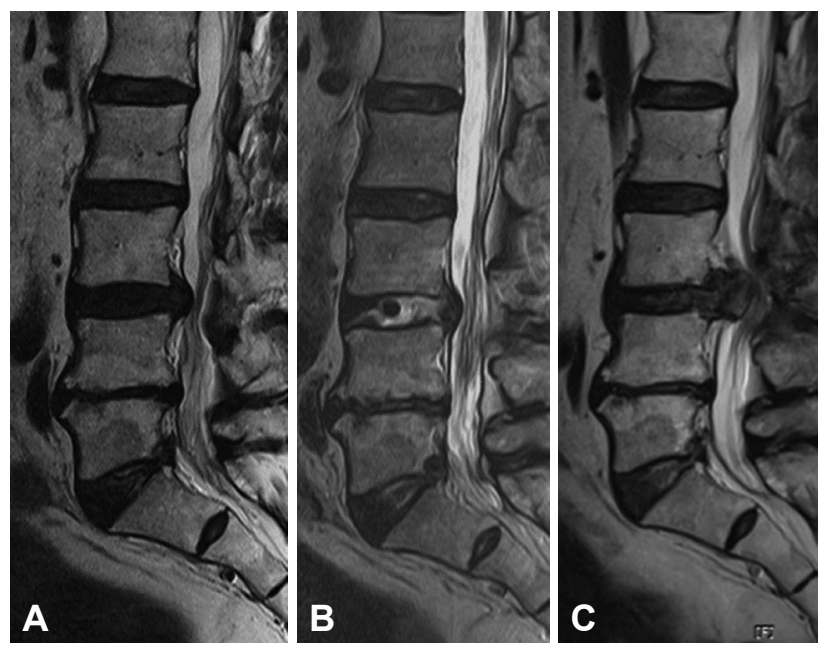

Fig. 1. Sagittal T2 MRI showing recurrent disc herniation at the L3/4 level. Initial MRI shows moderate disc protrusion at L3/4 (A). Follow-up MRI after first discectomy, post-operative day 7 . Recurrent disc herniation at L3/4 is noted (B). Post-operative 3 months after revision surgery. Extreme-large recurrent sequestration is noted $(1.97 \mathrm{~cm}$ in height, $1.52 \mathrm{~cm}$ in AP diameter) (C). 
$\operatorname{sac}$ (Fig. 1C).

Neurological examination showed decreased sensation on right L4, 5 dermatome and grade IV weakness at right ankle dorsiflexion. He was unable to walk due to worsening of symptoms. On account of neurologic deficit, we recommended additional surgery. However the patient refused due to fearful memory from repeated surgery. Furthermore, he had other several risk factors (old age, diabetes mellitus and chronic kidney disease) which made us to decide to treat conservatively.

Pain-relieving medication was administered and two sessions of spinal block therapy (at first session bilateral L4 transforaminal dorsal root ganglion and epidural block and L4, 5 ramus block was performed, at second session right side L4, 5 transforaminal dorsal root ganglion and epidural block and L3, 4, 5 ramus block was done) with injections of Triamcinolone (long-acting synthetic corticosteroid), dexamethasone, lidocaine, Hyrax (highly purified hyaluronidase) and one session of percutaneous radiofrequency ablation (pulsed dose radiofrequency ganglionotomy on bilateral L4 and medial branch neurotomy on right L4, 5) was performed with NeuroThermTM NT1000 RF lesion generator (Neurotherm Ltd., Surrey, UK). During 4 weeks of conservative treatments, his pain gradually improved. Initial Visual analog scale (VAS) for leg pain was 8 and decreased to VAS 2 after a month. Also, weakness of ankle was improved (motor grade IV to IV+). After 3 months, pain was relieved dramatically and the patient returned to daily activities.

\section{DISCUSSION}

The natural course of LDH is benign in majority cases as herniated disc regresses spontaneously ${ }^{2,11)}$. Three mechanisms are known to play a role in regression of herniated disc; dehydration of herniated disc, retraction of herniated disc and inflammatory reaction and neovasculization ${ }^{6,9,15,19,21,22)}$. Paradoxically, in the cases of large herniated disc, it shows obvious decrease in herniated disc size ${ }^{15,19,22)}$. In a 7-year follow-up study of Benson et al., $83 \%$ cases of massive ( $50 \%$ or more of the AP diameter of spinal canal) disc herniation have shown sustained improvement if there is early sign of clinical improvement and no evidence of significant complications ${ }^{4)}$. Nevertheless, many surgeons concern that conservative policy could prolong the period of suffering, leading to greater nerve damage or result in cauda equine syndrome.

According to the study of Weinstein et al., motor and sensory deficits present in $50-90 \%$ of patients with $\mathrm{LDH}^{25)}$. They compared the outcome of conservative and surgical treatments, and the latter showed better outcome ( $84.7 \%$ versus $95 \%$ of good or excellent results ${ }^{25)}$. Especially in patients with a cauda equine syndrome and in the presence of severe motor deficits of recent onset and/or with intractable pain, surgery could be indicated.18 However, except in these minor cases, $75-90 \%$ of patients with acute sciatica due to a protruded lumbar disc experience a resolution of symptoms without surgery ${ }^{10,15)}$. Hakelius reported that patients' weakness improve with time even though managed non-operatively, reporting that $80 \%$ of disc-herniated patients showed a major improvement after 6 weeks, $90 \%$ had improved after 12 weeks, and $93 \%$ had improved after 24 weeks. There was no advantage to be gained by operating on patients with a stable motor deficit (45\% of the conservativelytreated group improved and 53\% of the operated group improved, which shows no significant difference) $)^{12)}$. Other studies have supported these conclusions and suggested that $56 \%$ to $75 \%$ of patients recovered to Medical Research Council (MRC) grade 4 or 5 by six months ${ }^{14)}$.

Despite the fact that there were some degrees of motor and sensory function associated with extremely large sized disc in our case, we decided to try conservative treatment under the consideration of his old age, poor medical condition and psychologic factor. Another factor we speculated the factor of absence of severe neurological deficits, and thus decided initial non-operative treatment, in our patient was that previous laminectomy may have provided substantial space even though there was recurrent, huge disc protrusion. Soon after marked improvement seen after conservative treatments, we instituted the additional rehabilitation as its benefit has shown to reduce the prevent muscle wasting as well as to allow early resumption of daily living activities ${ }^{13)}$.

\section{CONCLUSION}

Conservative treatment, including interventional procedures, could be considered even in recurrent LDH patients with very large size who show mild neurological deficits, especially when patients do not show willingness for additional operation(s).

\section{REFERENCES}

1. Ahn SH, Ahn MW, Byun WM : Effect of the transligamentous extension of lumbar disc herniations on their regression and the clinical outcome of sciatica. Spine (Phila Pa 1976) 25 : 475-480, 2000

2. Autio RA, Karppinen J, Niinimaki J, Ojala R, Kurunlahti M, Haapea M, et al. : Determinants of spontaneous resorption of intervertebral disc herniations. Spine (Phila Pa 1976) 31 : 1247-1252, 2006

3. Benoist $\mathrm{M}$ : The natural history of lumbar disc herniation and radiculopathy. Joint Bone Spine 69 : 155-160, 2002

4. Benson RT, Tavares SP, Robertson SC, Sharp R, Marshall RW : Conservatively treated massive prolapsed discs : a 7-year follow-up. Ann R Coll Surg Engl 92 : 147-153, 2010

5. Bozzao A, Gallucci M, Masciocchi C, Aprile I, Barile A, Passariello R : Lumbar disk herniation: MR imaging assessment of natural history in patients treated without surgery. Radiology 185 : 135-141, 1992

6. Chang CW, Lai PH, Yip CM, Hsu SS : Spontaneous regression of lumbar herniated disc. J Chin Med Assoc 72 : 650-653, 2009

7. Cribb GL, Jaffray DC, Cassar-Pullicino VN : Observations on the natural history of massive lumbar disc herniation. J Bone Joint Surg Br 89 : 782-784, 2007

8. Delauche-Cavallier MC, Budet C, Laredo JD, Debie B, Wybier M, Dorfmann $\mathrm{H}$, et al. : Lumbar disc herniation. Computed tomography scan changes after conservative treatment of nerve root compression. Spine (Phila Pa 1976) 17 : 927-933, 1992 
9. Gezici AR, Ergun R : Spontaneous regression of a huge subligamentous extruded disc herniation : short report of an illustrative case. Acta Neurochir (Wien) 151 : 1299-1300, 2009

10. Gibson JN, Waddell G : Surgical interventions for lumbar disc prolapse. Cochrane Database Syst Rev (2) : Cd001350, 2007

11. Gregory DS, Seto CK, Wortley GC, Shugart CM : Acute lumbar disk pain : navigating evaluation and treatment choices. Am Fam Physician 78 : $835-842,2008$

12. Hakelius A : Prognosis in sciatica. A clinical follow-up of surgical and non-surgical treatment. Acta Orthop Scand Suppl 129: 1-76, 1970

13. Jacobs WC, van Tulder M, Arts M, Rubinstein SM, van Middelkoop M, Ostelo R, et al. : Surgery versus conservative management of sciatica due to a lumbar herniated disc : a systematic review. Eur Spine J 20 : 513-522, 2011

14. John J : Grading of muscle power : comparison of MRC and analogue scales by physiotherapists. Medical Research Council. Int J Rehabil Res 7 : 173-181, 1984

15. Komori H, Shinomiya K, Nakai O, Yamaura I, Takeda S, Furuya K : The natural history of herniated nucleus pulposus with radiculopathy. Spine (Phila Pa 1976) 21 : 225-229, 1996

16. Matsubara Y, Kato F, Mimatsu K, Kajino G, Nakamura S, Nitta H : Serial changes on MRI in lumbar disc herniations treated conservatively. Neuroradiology $37: 378-383,1995$

17. Modic MT, Ross JS, Obuchowski NA, Browning KH, Cianflocco AJ, Ma- zanec DJ : Contrast-enhanced MR imaging in acute lumbar radiculopathy : a pilot study of the natural history. Radiology 195 : 429-435, 1995

18. Postacchini F : Results of surgery compared with conservative management for lumbar disc herniations. Spine (Phila Pa 1976) 21 : 1383-1387, 1996

19. Ryu SJ, Kim IS : Spontaneous regression of a large lumbar disc extrusion. J Korean Neurosurg Soc 48 : 285-287, 2010

20. Saal JA, Saal JS, Herzog RJ : The natural history of lumbar intervertebral disc extrusions treated nonoperatively. Spine (Phila Pa 1976) 15 : 683-686, 1990

21. Sabuncuoglu H, Ozdogan S, Timurkaynak E : Spontaneous regression of extruded lumbar disc herniation : report of two illustrative case and review of the literature. Turk Neurosurg $18: 392-396,2008$

22. Slavin KV, Raja A, Thornton J, Wagner FC Jr : Spontaneous regression of a large lumbar disc herniation : report of an illustrative case. Surg Neurol 56 : 333-336; discussion 337, 2001

23. Valat JP, Genevay S, Marty M, Rozenberg S, Koes B : Sciatica. Best Pract Res Clin Rheumatol 24 : 241-252, 2010

24. Weber $\mathrm{H}$ : Lumbar disc herniation. A controlled, prospective study with ten years of observation. Spine (Phila Pa 1976) 8 : 131-140, 1983

25. Weinstein JN, Lurie JD, Tosteson TD, Skinner JS, Hanscom B, Tosteson AN, et al. : Surgical vs nonoperative treatment for lumbar disk herniation : the Spine Patient Outcomes Research Trial (SPORT) observational cohort. JAMA 296 : 2451-2459, 2006 